Freiwilligen durch zu akademische und verkopfte Debatten nicht kleingeredet und vor allem nicht zerredet wird. Dies wäre die einzige Sorge, die mir ein betont wissenschaftlicher Ansatz bereiten könnte: Bloß keine Überhöhung freiwilligen Engagements durch theorielastige Verwissenschaftlichung, sondern lieber ganz praktische Fragen in den Vordergrund rücken! Gespräche über die Organisation des freiwilligen Engagements sollen geführt, die Rolle des Staates in den Freiwilligendiensten angesprochen werden, aber eigentlich ist es doch ganz einfach: Von Freiwilligendiensten profitieren alle! Wer sich engagiert, tut nicht nur anderen etwas Gutes, sondern auch sich selbst. Denn diejenigen, die sich freiwillig für eine gute Sache engagieren, lernen viel für ihr privates und berufliches Leben oder ziehen Zufriedenheit daraus, dass sie andere Menschen an ihrer Lebenserfahrung teilhaben lassen. Die Menschen, die von Freiwilligen betreut werden, erfahren zusätzliche Aufmerksamkeit und Zuwendung und die Gesellschaft profitiert als Ganzes, wenn sich Menschen für andere Menschen oder für bestimmte Projekte einsetzen.

\title{
Engagement Global gGmbH - Service für Entwicklungsinitiativen
}

\author{
Gabriela Büssemaker \\ Hauptgeschäftsführerin der Engagement Global gGmbH \\ gabriela.buessemaker@engagement-global.de|www.engagement-global.de
}

Jeder der gehört werden will, muss reden. Jeder Redner braucht Zuhörer. Das ist das einfache Prinzip jedes Gesprächs. Damit

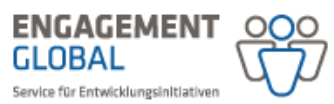
Menschen überhaupt miteinander ins Gespräch kommen, braucht es Gemeinsamkeiten - ob Interessen, Ideen oder Erfahrungen.

Freiwilligendienste bringen Menschen zusammen, die etwas in der Gesellschaft verändern und Verantwortung übernehmen wollen. Die Berichte der Freiwilligen über ihre Erlebnisse und Eindrücke sind es, die andere zuhören lassen. Sie geben neue Denkanstöße für die Bewältigung gesellschaftspolitischer Herausforderungen. Freiwilligendienste stehen dabei selbst vor neuen 
Aufgaben, wie beispielsweise der Erreichung weiterer Zielgruppen. Um dabei kritisch mit der eigenen Rolle umgehen zu können, braucht es einen offenen Dialog mit dem Umfeld. Voluntaris - Zeitschrift für Freiwilligendienste sollte ein Forum für all jene bieten, die ihr Wissen und ihre Erkenntnisse aus Forschung und Praxis in eine konstruktive Diskussion rund um Freiwilligendienste einbringen wollen.

Engagement Global gGmbH - Service für Entwicklungsinitiativen ist die Ansprechpartnerin in Deutschland für entwicklungspolitisches Engagement, deutschlandweit und international. Unter unserem Dach vereinen wir unter anderem die Koordinierungsstellen des entwicklungspolitischen Freiwilligendienstes weltwärts und des Senior Expert Service sowie die Austauschund Bildungsprogramme ASA und ENSA. Wir beraten, verstehen uns aber auch selbst als Teil unserer Lerndienste. Für die Bearbeitung globaler Themen und die Weiterentwicklung unserer Programme nehmen wir immer wieder Impulse von außen auf. Auf solche Impulse freuen wir uns von Fachzeitschriften wie Voluntaris.

Wichtig ist aus unserer Sicht, die Perspektive der Freiwilligen einzubinden. Egal ob jung oder alt, Frau oder Mann - sie sind diejenigen, um die es geht. Voluntaris sollte ihr Interesse an Freiwilligendienstpolitik und Entwicklungspolitik befördern, ihnen Räume eröffnen, in denen sie aktuelle Themen mit entwickeln können und sie in ihrem Engagement bestärken.

Voluntaris kann darüber hinaus einen wichtigen Beitrag für die gesamte Szene um Freiwilligendienste in Deutschland leisten. Viele Programme, ob national, international oder entwicklungspolitisch, stehen vor denselben gesellschaftlichen Herausforderungen. Synergien können durch den Austausch ihrer Erfahrungen aus Studien, Programmen, Konzepten und Pilotprojekten erzeugt werden. Wir freuen uns, wenn Voluntaris von allen Akteuren aus Wissenschaft, Praxis und Politik als ein solches Dialog-Forum verstanden und wahrgenommen wird - wir selbst bringen uns gerne in den Fachdiskurs mit unserer Expertise und Erfahrungen ein und sind gespannt, welche Erkenntnisse die Zeitschrift für unsere Arbeit eröffnet.

Eine unabhängige Zeitschrift zu Freiwilligendiensten sollte anstoßend und verbindend wirken, anregend und aufregend sein, konstruktiv provozieren und eine gemeinsame Plattform für unterschiedliche Akteure sein, die dort in Dialog treten. Dafür wünsche ich Voluntaris zum Start gutes Gelingen! 